\title{
Cognitive Function of Korean Neurosurgical Patients: Cross-sectional Study Using the Korean Version of the Mini-mental Status Examination
}

\author{
Jiha Kim, MD, ${ }^{1}$ Chi Heon Kim, MD, PhD, ${ }^{2,3,4}$ Hyun-Seung Kang, MD, PhD, ${ }^{2,3,4}$ \\ Chul-Kee Park, MD, PhD, ${ }^{2,3,4}$ Chun Kee Chung, MD, PhD $2,3,4$ \\ Department of Neurosurgery, Kangwon National University Hospital, ${ }^{1}$ Department of Neurosurgery, Seoul National \\ University Hospital, ${ }^{2}$ Neuroscience Research Institute, Seoul National University Medical Research Center, ${ }^{3}$ Clinical \\ Research Institute, Seoul National University Hospital, Seoul, Korea ${ }^{4}$
}

\begin{abstract}
Objective: As interest in life quality and expectancy increases, cognitive dysfunction is becoming an important topic. Although there are many foreign articles on this topic, they require cultural interpretation to be applicable to Koreans. The purpose of this study was to assess cognitive function in Korean neurosurgical patients. Methods: We recruited 214 adult Korean patients with various cerebral pathologies and treatments from an outpatient clinic. The male-to-female ratio was 88:126, and their ages ranged from 28 to 81 years (mean: 57.9 years). The Korean version of the mini-mental status examination (K-MMSE) was adopted as an instrument for measuring cognitive function, and a score $\leq 23$ was defined as cognitive dysfunction. K-MMSE scores were analyzed considering the patients' gender, age, time elapsed since treatments, pathology and treatment modality. A serial analysis was performed for 59 patients who completed the K-MMSE more than once. Results: The mean K-MMSE score of 214 patients was 22.3, and 133 patients (62.1\%) had a score $\leq 23$. Cognitive dysfunction was common regardless of age, gender, pathology or treatment modality. Serial analysis revealed K-MMSE score improvement in 45 of 59 patients (76.3\%). The mean time interval between two tests was 11.9 months, and the mean K-MMSE score improvement was 2.7, which was statistically significant $(P=0.000)$. However, many still had cognitive impairment. Conclusion: Most Korean neurosurgical patients showed cognitive dysfunction despite improvement after several months. Patients with trauma or ischemic disease were more vulnerable. More attention should be paid to neuropsychological complications such as cognitive dysfunction.
\end{abstract}

(J Cerebrovasc Endovasc Neurosurg. 2012 Mar;14(1):11 21)

KEY WORDS Cognitive dysfunction · Craniotomy $\cdot$ Korea $\cdot$ MMSE $\cdot$ Neurosurgery

Received : 5 December 2011

Revised : 4 January 2012

Accepted : 1 February 2012

Corresponding Author : Chun Kee Chung, MD, PHD

Address: Department of Neurosurgery, Seoul National University

Hospital, 28 Yeongeon-dong, Jongno-gu Seoul, 110-744, South

Korea

Tel : (001) 82-2-2072-2352 Fax : (001) 82-2-744-8459

E-mail : chungc@snu.ac.kr

\section{INTRODUCTION}

Public interest in quality of life is increasing with the improvement of general health and economic conditions. Many studies are now being conducted that focus on both mental and physical health. An increasing elderly population is also enhancing the number of studies on cognitive impairment. ${ }^{7}$ As Korean life expectancy in- 
creases, interest in cognitive impairment, including dementia, continues to increase. ${ }^{7) 910)}$

Although there are many published articles about cognitive function, most articles focus on non-surgical diseases or population-based cognitively normal groups. ${ }^{79) 10)}$ Moreover, most published postoperative reports are on foreign patients who have different cultural backgrounds. 1)13-15)18)20)22)23) Compared with foreign countries, a relatively small number of studies have been conducted in Korea. Although many diseases and neurosurgical procedures have the potential to cause cognitive impairment, only limited information is available in the Korean neurosurgical field.

This paucity of information is likely to stem from the lack of previous normative data and a verified measuring instrument. ${ }^{7)}$ There are many difficulties in applying knowledge from foreign articles directly to Korean patients. Cognitive functional evaluation results can be influenced by many individual socio-cultural factors, such as age, gender, race and education level; unlike other clinical or laboratory tests, they require cultural interpretation and compensation. ${ }^{3) 577) 17)}$ In addition, there are deviations when certain measuring instruments are applied. Although many instruments have been designed to measure the cognitive function of various groups, most of them were written in English and adapted to Western socio-cultural conditions. Therefore, they are difficult to apply directly to Korean patients who have different socio-cultural background; these assessments need to be translated and adapted according to Korean cultural backgrounds. ${ }^{7) 13)}$

Here, we present the cognitive function assessment results of 214 Korean neurosurgical patients who visited a neurosurgical outpatient clinic. We used the Korean version of the mini-mental status examination (K-MMSE) questionnaire as a measuring instrument. Our study includes patients with various pathologies who underwent surgical or interventional procedures. The aim of this cross-sectional study was to present a general perspective on the cognitive functional state of Korean neurosurgical patients, rather than detailed in- formation about specific diseases or procedures.

\section{MATERIALS AND METHODS}

We conducted this cross-sectional study in patients who visited the outpatient clinic of the Department of Neurosurgery in our hospital between January 2009 and December 2010. All of them underwent either brain surgery or endovascular intervention. The male-to-female ratio was $88: 126$, and their ages ranged from 28 to 81 years (mean: 57.9 years) (Fig. 1). They presented with a range of cerebral pathologies including aneurysm, cerebral ischemic disease, vascular anomaly, spontaneous hemorrhage, tumor, epilepsy and trauma. They underwent various treatment modalities, such as aneurysm clipping, endovascular coiling, vascular anastomosis, tumor surgery and epilepsy surgery. The time interval from treatment to study ranged from 1 to 194 months (mean: 30.9 months) (Table 1). We excluded pediatric patients under 15 years of age and those who refused to fill out our questionnaires or had poor compliance.

In our study, the K-MMSE questionnaire was adopted as an instrument to measure cognitive function (Fig. 2). All patients spoke Korean as their first language and did not experience any linguistic difficulties in filling out our questionnaire. Considering many other published our questionnaire. Considering many other published articles

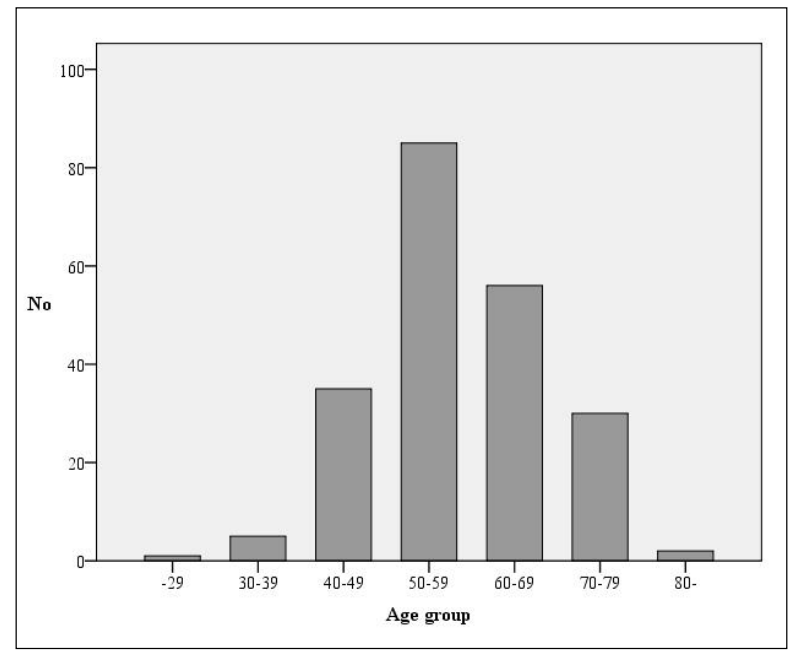

Fig. 1. Bar graphs showing the age distribution of 214 patients. 
Table 1. Summary of disease and treatment modalities in the patient cohort

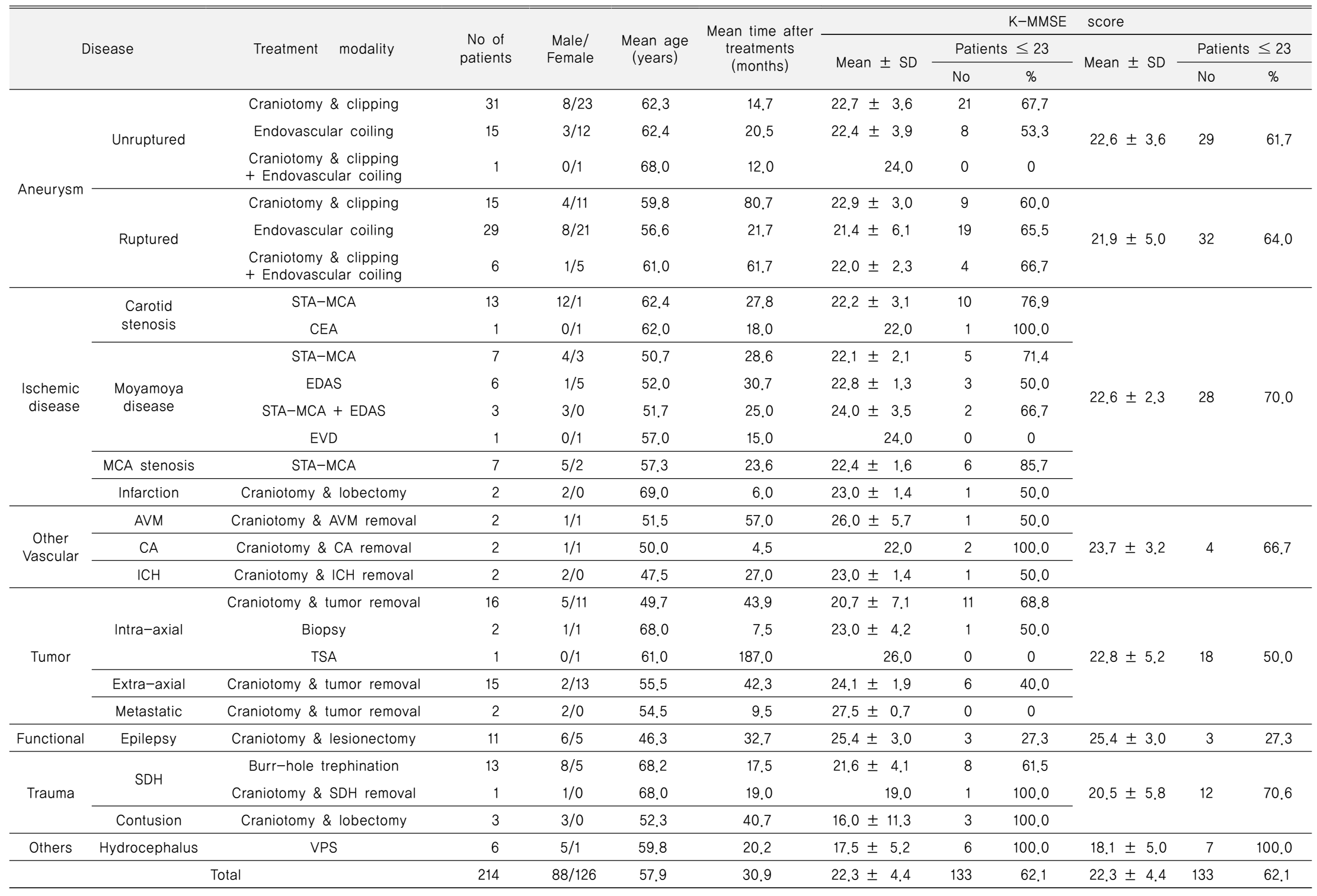

K-MMSE = Korean mini-mental status examination; SD = standard deviation; STA-MCA = Superficial temporal artery-middle cerebral artery anastomosis; CEA = Carotid endarterectomy; EDAS =

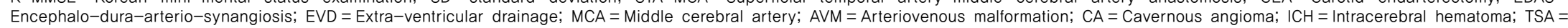

Trans-sphenoidal approach; SDH = Subdural hematoma; VPS = Ventriculo-peritoneal shunt; ACM = Arnold-Chiari malformation; FMD = Foramen magnum decompression 
Date

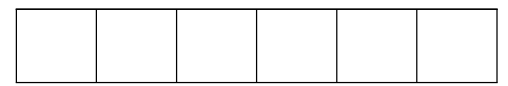

Baseline

Endpoint

K-MMSE ( Mini-Mental State Examination )

$1 / 1$

\begin{tabular}{|c|c|c|c|c|c|}
\hline 항 목 & & & 반 응 & 점수 & 합계 \\
\hline \multirow{5}{*}{$\begin{array}{c}\text { 시간 지남력 } \\
\text { [5] }\end{array}$} & \multicolumn{2}{|c|}{ 년 (1) } & & & \\
\hline & \multicolumn{2}{|c|}{ 월 (1) } & & & \\
\hline & \multicolumn{2}{|c|}{ 일 (1) } & & & 점 \\
\hline & \multicolumn{2}{|c|}{ 요일 (1) } & & & \\
\hline & \multicolumn{2}{|c|}{ 계절 (1) } & & & \\
\hline \multirow{5}{*}{$\begin{array}{c}\text { 장소 지남력 } \\
\text { (장소) } \\
\text { [5] }\end{array}$} & \multicolumn{2}{|c|}{ 나라 (1) } & & & \\
\hline & \multicolumn{2}{|c|}{ 시, 도 (1) } & & & \\
\hline & \multicolumn{2}{|c|}{ 무엇하는 곳 (1) } & & & 점 \\
\hline & \multicolumn{2}{|c|}{ 현재 장소명 (1) } & & & \\
\hline & \multicolumn{2}{|c|}{ 몇 층 (1) } & & & \\
\hline \multirow{3}{*}{$\begin{array}{c}\text { 기억 등록 } \\
\text { [3] }\end{array}$} & \multicolumn{2}{|c|}{ 비행기 (1) } & & & \\
\hline & \multicolumn{2}{|c|}{ 연필 (1) } & & & 점 \\
\hline & \multicolumn{2}{|c|}{ 소나무 (1) } & & & \\
\hline \multirow{5}{*}{$\begin{array}{l}\text { 주의 집중 } \\
\text { 및 계산 } \\
\text { [5] }\end{array}$} & \multicolumn{2}{|c|}{$100-7$ (1) } & & & \\
\hline & \multicolumn{2}{|c|}{$-7(1)$} & & & \\
\hline & \multicolumn{2}{|c|}{$-7(1)$} & & & 점 \\
\hline & \multicolumn{2}{|c|}{$-7(1)$} & & & \\
\hline & \multicolumn{2}{|c|}{$-7(1)$} & & & \\
\hline \multirow{3}{*}{$\begin{array}{c}\text { 기억 회상 } \\
\text { [3] }\end{array}$} & \multicolumn{2}{|c|}{ 비행기 (1) } & & & \\
\hline & \multicolumn{2}{|c|}{ 연필 (1) } & & & 점 \\
\hline & \multicolumn{2}{|c|}{ 소나무 (1) } & & & \\
\hline \multirow{6}{*}{$\begin{array}{c}\text { 언어 및 } \\
\text { 시공간 구성 } \\
\text { [9] }\end{array}$} & 이름 대기 (2) & 시계, 볼펜 & $\begin{array}{l}1 \square \text { 시계 } \\
1 \square \text { 볼펜 }\end{array}$ & & \\
\hline & \multicolumn{2}{|c|}{ 명령 시행 (3) } & $\begin{array}{l}1 \square \text { 종이를 뒤ㅈㅣㅣㄱㅗ } \\
1 \square \text { 반으로 접은 다음 } \\
1 \square \text { 저에게 주세요 }\end{array}$ & & \\
\hline & 따라 말하기 (1) & 백문이 불여일견 & & & 점 \\
\hline & 오각형 (1) & $\infty$ & & & \\
\hline & 읽기 (1) & 눈을 감으세요. & & & \\
\hline & 쓰기 (1) & 오늘 기분이나 는 & 씨에 대해 써 보십시오. & & \\
\hline 총 점 & & & & & \\
\hline
\end{tabular}

Fig. 2. The questionnaire for the Korean mini-mental status examination (K-MMSE).

and our patient distribution, a K-MMSE score $\leq 23$ was defined as the cut-off for decreased cognitive function.

The K-MMSE scores were analyzed considering the patients' gender, age, time after treatments, pathologies and treatment modalities. We retrospectively reviewed their medical records and radiological data, such as magnetic resonance imaging, computed tomography or angiography.

First, we classified each patient according to his or her pathologies and treatment modalities (Table 1). Then, we compared the K-MMSE score of 214 patients using a 
fixed cut-off value of 23. For patients who completed our questionnaire more than once, only the first score was used for this analysis.

Next, we analyzed the score after stratifying by gender and age. We also compared significant differences between genders in every age group using the MannWhitney test or the $t$-test.

Third, we analyzed the data collected from 90 aneurysm patients to determine the effect of pathologies or treatment modalities on cognitive function. We classified them into four groups according to their pathologies (unruptured or ruptured) and treatment modalities (endovascular coiling or clipping). Then, we compared the K-MMSE scores of each group using the MannWhitney tests. Seven patients who had both treatments were excluded in this analysis.

Next, we analyzed cognitive function changes by time interval. There were 59 patients $(27.6 \%)$ who completed the K-MMSE more than once at different times. From 42 patients who answered twice, all scores were used. From 17 patients who answered 3 times or more, only the first and last scores were used. There were 13 and 4 patients who answered 3 and 4 times, respectively. We compared their last K-MMSE score with their first one using Wilcoxon signed-ranks test or paired $t$-test.

In this study, every comparison or analysis of K-MMSE scores was conducted using a fixed cut-off value of 23 , and a $p$-value $<0.05$ was considered stat- istically significant. All data analyses were performed with commercially available statistical software (SPSS version 17.0, SPSS Inc., Chicago, IL, USA).

\section{RESULTS}

\section{General description}

The mean K-MMSE score of all 214 patients was 22.3, and 133 patients $(62.1 \%)$ had a K-MMSE score $\leq 23$. The decreased K-MMSE score was obvious in most pathologies, including unruptured aneurysm (61.7\%), ruptured aneurysm $(64.0 \%)$, ischemic disease (70.0\%) and trauma $(70.6 \%)$, although there were some differences according to their treatment modalities. The proportion of patients with a K-MMSE score $\leq 23$ was the highest in trauma and ischemic disease and the lowest in epilepsy and tumor patients $(27.3 \%$ and $50.0 \%$, respectively) (Table 1).

\section{Effect of age and gender}

A decreased K-MMSE score was prevalent in almost all age groups, regardless of gender. In age groups older than 39 years, over $60.0 \%$ of patients had a K-MMSE score $\leq 23$. Inter-gender differences were not statistically significant in all age groups. Although the overall mean K-MMSE score was higher in males than in females (22.7 and 22.0, respectively), this difference was not statistically significant ( $p=0.285$, using $t$-test) (Table 2 ).

Table 2. Patient summary according to gender and age group

\begin{tabular}{|c|c|c|c|c|c|c|c|c|c|c|c|c|c|}
\hline \multirow{4}{*}{ Age group } & \multicolumn{4}{|c|}{ Male } & \multicolumn{4}{|c|}{ Female } & \multirow{4}{*}{$p$-value } & \multicolumn{4}{|c|}{ Total } \\
\hline & \multirow{3}{*}{$\begin{array}{l}\text { No of } \\
\text { patients }\end{array}$} & \multicolumn{3}{|c|}{ K-MMSE score } & \multirow{3}{*}{$\begin{array}{l}\text { No of } \\
\text { patients }\end{array}$} & \multicolumn{3}{|c|}{ K-MMSE score } & & \multirow{3}{*}{$\begin{array}{l}\text { No of } \\
\text { patients }\end{array}$} & \multicolumn{3}{|c|}{ K-MMSE score } \\
\hline & & \multicolumn{2}{|c|}{ Patients $\leq 23$} & \multirow{2}{*}{ Mean \pm SD } & & \multicolumn{2}{|c|}{ Patients $\leq 23$} & \multirow{2}{*}{ Mean \pm SD } & & & \multicolumn{2}{|c|}{ Patients $\leq 23$} & \multirow{2}{*}{ Mean $\pm S D$} \\
\hline & & No & $\%$ & & & No & $\%$ & & & & No & $\%$ & \\
\hline-39 & 3 & 0 & 0 & $27.0 \pm 2.6$ & 3 & 0 & 0 & $29.0 \pm 1.0$ & $0.261^{*}$ & 6 & 0 & 0 & $28.0 \pm 2.1$ \\
\hline $40-49$ & 18 & 10 & 55.6 & $23.1 \pm 6.3$ & 17 & 11 & 64.7 & $22.0 \pm 3.9$ & $0.100^{*}$ & 35 & 21 & 60.0 & $22.5 \pm 5.2$ \\
\hline $50-59$ & 30 & 19 & 63.3 & $23.7 \pm 3.6$ & 55 & 34 & 61.8 & $22.2 \pm 4.2$ & $0.105^{\dagger}$ & 85 & 53 & 62.4 & $22.7 \pm 4.1$ \\
\hline $60-69$ & 22 & 16 & 72.7 & $21.8 \pm 4.4$ & 34 & 22 & 64.7 & $22.3 \pm 2.8$ & $0.952^{*}$ & 56 & 38 & 67.9 & $22.1 \pm 3.5$ \\
\hline $70-$ & 15 & 9 & 60.0 & $20.9 \pm 4.7$ & 17 & 12 & 70.6 & $20.0 \pm 5.5$ & $0.620^{*}$ & 32 & 21 & 65.6 & $20.4 \pm 5.1$ \\
\hline Total & 88 & 54 & 61.4 & $22.7 \pm 4.7$ & 126 & 79 & 62.7 & $22.0 \pm 4.2$ & $0.285^{\dagger}$ & 214 & 133 & 62.1 & $22.3 \pm 4.4$ \\
\hline
\end{tabular}




\section{Effect of pathology and treatment modality}

We classified 90 aneurysm patients into four groups; group A (unruptured aneurysm, clipping), group B (unruptured aneurysm, endovascular coiling), group $\mathrm{C}$ (ruptured aneurysm, clipping) and group D (ruptured aneurysm, endovascular coiling) (Table 3). The proportion of patients in these groups with a K-MMSE score $\leq 23$ was $67.7 \%, 53.3 \%, 60.0 \%$ and $65.5 \%$, respectively. However, there was no statistically significant difference when patients were divided by treatment modality (group A vs. B and C vs. D, $p=0.914$ and 0.478 , respectively). There was also no difference in K-MMSE score between patients with unruptured vs. ruptured aneurysms (group A vs. C and group B vs. D, $p=0.802$ and 0.550 , respectively).

Table 3. Summary of aneurysm patients according to treatment modality

\begin{tabular}{|c|c|c|c|c|c|c|c|c|c|c|c|c|}
\hline \multirow{3}{*}{ Aneurysm } & \multirow{3}{*}{$\begin{array}{l}\text { Treatment } \\
\text { modality }\end{array}$} & \multirow{3}{*}{$\begin{array}{l}\text { No of } \\
\text { patients }\end{array}$} & \multirow{3}{*}{$\begin{array}{l}\text { Male/ } \\
\text { Female }\end{array}$} & \multirow{3}{*}{$\begin{array}{l}\text { Mean age } \\
\text { (years) }\end{array}$} & \multirow{3}{*}{$\begin{array}{l}\text { Mean time } \\
\text { after } \\
\text { treatments } \\
\text { (months) }\end{array}$} & \multicolumn{6}{|c|}{ K-MMSE score } & \multirow{3}{*}{ Groups } \\
\hline & & & & & & \multicolumn{3}{|c|}{ No of patients } & \multicolumn{2}{|c|}{ \%) } & \multirow[b]{2}{*}{ Mean \pm SD } & \\
\hline & & & & & & $\leq 20$ & $21-23$ & 24 & $\begin{array}{c}25-2 \\
6\end{array}$ & $27-30$ & & \\
\hline \multirow{2}{*}{ Unruptured } & Clipping & 31 & $8 / 23$ & 62.3 & 14.7 & $2(6.5)$ & $19(61.3)$ & $7(22.6)$ & 0 & $3(9.7)$ & $22.7 \pm 3.6$ & A \\
\hline & Coiling & 15 & $3 / 12$ & 62.4 & 20.5 & $4(26.7)$ & $4(26.7)$ & $5(33.3)$ & 0 & $2(13.3)$ & $22.4 \pm 3.9$ & B \\
\hline \multirow{2}{*}{ Ruptured } & Clipping & 15 & $4 / 11$ & 59.8 & 80.7 & $3(20.0)$ & $6(40.0)$ & $4(26.7)$ & 0 & $2(13.3)$ & $22.9 \pm 3.0$ & C \\
\hline & Coiling & 29 & $8 / 21$ & 56.6 & 21.7 & $9(31.0)$ & $10(34.5)$ & $3(10.3)$ & 0 & $7(24.1)$ & $21.4 \pm 6.1$ & D \\
\hline
\end{tabular}

Clipping = Craniotomy and clipping; Coiling = Endovascular coiling

Table 4. Summary of the patients who completed the K-MMSE questionnaire more than once

\begin{tabular}{|c|c|c|c|c|c|c|c|c|c|}
\hline \multirow{3}{*}{ Disease } & \multirow{3}{*}{ Treatment modality } & \multirow{3}{*}{$\begin{array}{l}\text { No of } \\
\text { patients }\end{array}$} & \multirow{3}{*}{$\begin{array}{l}\text { Male/ } \\
\text { Female }\end{array}$} & \multirow{3}{*}{$\begin{array}{l}\text { Mean age } \\
\text { (years) }\end{array}$} & \multirow{3}{*}{$\begin{array}{l}\text { Mean time } \\
\text { after } \\
\text { treatments } \\
\text { (months) }\end{array}$} & \multicolumn{4}{|c|}{ K-MMSE score } \\
\hline & & & & & & \multirow{2}{*}{$\begin{array}{c}\text { Mean } \\
\text { interval* }^{*} \\
\text { (months) }\end{array}$} & \multicolumn{2}{|c|}{ Mean $\pm \mathrm{SD}$} & \multirow{2}{*}{$p$ value } \\
\hline & & & & & & & First & Last & \\
\hline \multirow{3}{*}{$\begin{array}{l}\text { Unruptured } \\
\text { aneurysm }\end{array}$} & Craniotomy \& clipping & 13 & $3 / 10$ & 64.8 & 12.4 & \multirow{2}{*}{11.6} & \multirow{2}{*}{$21.9 \pm 4.1$} & \multirow{2}{*}{$25.6 \pm 5.6$} & \multirow{2}{*}{$0.001^{\dagger}$} \\
\hline & Endovascular coiling & 6 & $1 / 5$ & 65.0 & 14.8 & & & & \\
\hline & Craniotomy \& clipping & 5 & $0 / 5$ & 51.2 & 59.4 & & & & \\
\hline \multirow{3}{*}{ Ruptured aneurysm } & Endovascular coiling & 9 & $3 / 6$ & 66.2 & 27.6 & \multirow{2}{*}{11.5} & \multirow{2}{*}{$20.2 \pm 5.0$} & \multirow{2}{*}{$24.3 \pm 6.0$} & \multirow[t]{2}{*}{$0.013^{\dagger}$} \\
\hline & $\begin{array}{l}\text { Craniotomy \& clipping } \\
+ \text { Endovascular coiling }\end{array}$ & 2 & $0 / 2$ & 66.5 & 87.0 & & & & \\
\hline & STA-MCA & 3 & $2 / 1$ & 54.3 & 22.0 & \multirow{7}{*}{11.2} & \multirow{7}{*}{$22.4 \pm 2.7$} & \multirow{7}{*}{$21.9 \pm 7.0$} & \multirow{7}{*}{$0.700^{\dagger}$} \\
\hline \multirow[t]{2}{*}{ Moyamoya disease } & EDAS & 1 & $0 / 1$ & 52.0 & 7.0 & & & & \\
\hline & STA-MCA+ EDAS & 2 & $2 / 0$ & 53.5 & 24.0 & & & & \\
\hline Carotid stenosis & STA-MCA & 3 & $3 / 0$ & 69.0 & 40.0 & & & & \\
\hline MCA stenosis & STA-MCA & 1 & $1 / 0$ & 68.0 & 18.0 & & & & \\
\hline $\mathrm{CA}$ & Craniotomy \& CA removal & 1 & $1 / 0$ & 50.0 & 6.0 & & & & \\
\hline $\mathrm{ICH}$ & Craniotomy \& ICH removal & 2 & $2 / 0$ & 47.5 & 27.0 & & & & \\
\hline \multirow{2}{*}{ SDH } & Burr-hole trephination & 3 & $2 / 1$ & 72.7 & 22.3 & \multirow{2}{*}{15.5} & \multirow{2}{*}{$22.5 \pm 2.4$} & \multirow{2}{*}{$25.5 \pm 3.0$} & \multirow{2}{*}{$0.109^{\dagger}$} \\
\hline & Craniotomy \& lobectomy & 1 & $1 / 0$ & 68.0 & 19.0 & & & & \\
\hline Intra-axial tumor & Craniotomy \& tumor removal & 3 & $1 / 2$ & 51.0 & 75.3 & 12.0 & $21.7 \pm 3.1$ & $23.3 \pm 5.5$ & $0.276^{\dagger}$ \\
\hline Epilepsy & Craniotomy \& lesionectomy & 2 & $0 / 2$ & 49.5 & 24.5 & 13.0 & $22.0 \pm 1.4$ & $29.0 \pm 1.4$ & $0.180^{\dagger}$ \\
\hline \multirow[t]{2}{*}{ Hydrocephalus } & VPS & 2 & $2 / 0$ & 53.0 & 40.0 & 15.0 & $21.0 \pm 2.8$ & $20.0 \pm 4.2$ & $0.655^{\dagger}$ \\
\hline & Total & 59 & $24 / 35$ & 61.1 & 29.3 & 11.9 & $21.6 \pm 3.9$ & $24.2 \pm 5.9$ & $0.000^{\dagger}$ \\
\hline
\end{tabular}

${ }^{*}$ Mean interval = mean time interval from first to last $\mathrm{K}$-MMSE score; $p$-value= difference between first and last $\mathrm{K}$-MMSE score using Wilcoxon signed-ranks test $\left({ }^{\dagger}\right)$ or paired $t$-test $\left(^{\ddagger}\right)$ 


\section{Effect of time}

From 59 patients $(27.6 \%)$ who completed the K-MMSE more than once, the first and last scores were compared. Their mean time after treatment was 29.3 months, and the mean time interval between test administrations was 11.9 months. The number of patients with a K-MMSE score $\leq 23$ was 41 and $18(69.5 \%$ and $30.5 \%)$ for the first and the last test, respectively. The mean K-MMSE score difference was 2.7 , which was statistically significant ( $p=0.000$, using paired $t$-test) (Table 4). In all, 45 of 59 patients $(76.3 \%)$ had an improved K-MMSE score. These improvements were notable in unruptured and ruptured aneurysm groups $(89.5 \%$ and $75.0 \%$, respectively). However, patients with vascular disease, such as Moyamoya disease or carotid stenosis had decreased K-MMSE scores, although these changes were not statistically significant $(p=0.700$, using Wilcoxon signed-ranks test) (Table 4$)$. The linear correlation between the time interval and the K-MMSE score change was not definite in the unruptured or ruptured aneurysm groups $\left(\mathrm{R}^{2}=0.078\right.$ and 0.002 , respectively).

\section{DISCUSSION}

\section{Study design}

The purpose of this cross-sectional study was to measure the cognitive function of general neurosurgical patients. To measure the effect of disease or treatment modality on cognitive function, a case-control or comparative study can be good designs to compare two sets of data obtained from cases and controls or from the same individual before and after a procedure. However, these study designs are not always powerful. For example, in slowly progressing diseases such as tumor, we do not always know its outbreak to obtain initial data to use as a baseline. In emergency conditions, such as cerebral hemorrhage or trauma, we are also unable to know when we should obtain initial baseline data. Therefore, we thought the cross-sectional study design was a good choice to overcome these difficulties.

\section{Measuring instrument}

The MMSE was originally developed to evaluate elderly psychiatric patients. ${ }^{6) 10}$ Although it is the most widely used screening instrument for dementia or cognitive dysfunction, it has some limitations. ${ }^{7) 910)}$ First, it cannot be fully administered to disabled individuals with motor impairment because it contains performance tests that assess praxis and visuospatial function. ${ }^{10)}$ Therefore, we conducted our study in an outpatient clinic setting to exclude patients who were either in an acute postoperative period or critical condition. We also excluded those who never had brain surgery or interventions to maintain homogeneity of our case population; most of them had either very mild symptoms or very critical problems that were inoperable, and we thought they might cause a bias and skew the results. Second, it is difficult to distinguish postoperative cognitive dysfunction from postoperative delirium using the MMSE. ${ }^{19) 21)}$ By conducting an outpatient clinic based-study, we excluded postoperative delirium, which tends to be a transient and fluctuating disturbance of consciousness that occurs shortly after surgery, whereas postoperative cognitive dysfunction is a more persistent problem of cognitive performance that can be assessed by neuropsychological tests. ${ }^{16)}$ Our patients' mean time from treatment to study was 30.9 months, and over 60\% (130 of 214) of patients participated more than 1 year after treatment. Third, the MMSE needs to be translated and adapted to the Korean cultural background.' ${ }^{7}$ Because simply translating the tests into foreign languages would not provide comparative results, we needed to adopt a verified measuring instrument. ${ }^{7) 13)}$

The MMSE was modified and translated into Korean by Kang et al., and the resulting K-MMSE has been widely used in clinical evaluations and research involving Korean dementia patients. ${ }^{79)}$ We defined a K-MMSE score $\leq 23$ as the cut-off value for abnormal cognitive function for two reasons. First, it was used as a cut-off value in many other articles. ${ }^{4) 911) 14) 21)}$ With the same cut-off value, we can share established knowledge with 


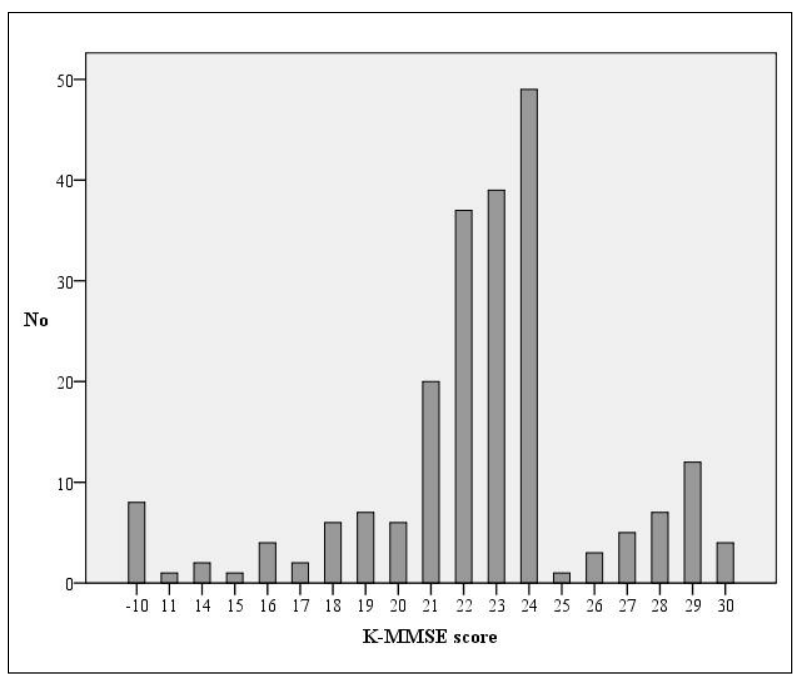

Fig. 3. Bar graphs showing the distribution of the Korean mini-mental status examination (K-MMSE) score of 214 patients.

other studies and compare them with ours. Second, we thought 23 is reasonable cut-off value, considering the mean K-MMSE score measured by Han et al. in 977 normal elderly Koreans. ${ }^{7)}$ Although there are some variations according to age, gender and education level, the mean K-MMSE score of each group ranged from 23.3 to 27.7 . $^{7)}$ Setting the cut-off value was very critical because more than $20 \%$ of patients (49 out of 214) were clustered around a score of 24 in our series, and this number was equivalent to more than half of normal patients (Fig. 3). If the cut-off value was 24 instead of 23 , the percentage of normal patients would decrease from $37.9 \%$ to $15.0 \%$.

\section{High incidence of cognitive dysfunction}

More than $62 \%$ of patients (133 out of 214) had $\mathrm{K}$-MMSE scores $\leq 23$, and this decrease was common in almost all pathologies and treatment modalities in our study (Table 1). After stratification according to gender and age, most groups still had an average K-MMSE score $\leq 23$. There was no statistically significant difference between genders (Table 2). In other articles, cognitive dysfunction has been documented in up to $50 \%$ of patients who have experienced subarachnoid hemorrhage. ${ }^{11) 12)}$ Several studies gave incidence estimates for post-stroke dementia that range between 6 and 32\%. ${ }^{2}$ Compared with other type of surgery, patients who undergo brain surgery seem to be more vulnerable to cognitive dysfunction. Abildstrom et al. ${ }^{1)}$ reported $10.4 \%$ of patients who underwent major abdominal, non-cardiac thoracic, or orthopedic surgery with general anesthesia had cognitive dysfunction 1-2 year postoperatively. Moller et al. ${ }^{14)}$ also demonstrated that $9.9 \%$ of patients had cognitive dysfunction 3 months postoperatively. Although it is difficult to directly compare our results with other articles because of different study populations and various measurement instruments, our proportion seems much higher than that reported for non-brain surgery. We believe this difference stems from effects on the brain itself, either by pathologies or by treatments. Some studies on general versus regional or spinal anesthesia have not found differences in postoperative cognitive dysfunction. ${ }^{4) 16)}$ We think postoperative cognitive dysfunction is affected more by the type of surgery than anesthesia. Cognitive impairment was documented in up to $50 \%$ of patients of cardiac surgery patients. ${ }^{8) 15 / 23)}$ This is because cardiac surgery is a lot similar to brain surgery in that cardiopulmonary bypass is thought to have cerebral effect. ${ }^{14) 16) 23 \text { ) }}$

\section{Differences according to pathologies or treatment modalities}

To figure out if the K-MMSE score was influenced by different pathologies or treatment modalities, we analyzed the data collected from aneurysm patients (Table 3). Because both unruptured and ruptured aneurysms share the same treatment modalities, we could analyze the effect of pathologies when the effect of treatment modalities was controlled (group A vs. C and B vs. D). At the same time, we could analyze the effect of treatment modalities when the effect of pathology type was controlled (group A vs. B and C vs. D). Because ruptured aneurysms develop from unruptured aneurysms, we expected to estimate the additive effect of subarachnoid hemorrhage. However, we failed to find significant dif- 
ferences in each analysis. There was no difference between pathologies or treatment modalities. Considering the articles that report no cognitive function change after craniotomy for unruptured aneurysm, ${ }^{20) 22)}$ it is reasonable that there was no difference between clipping and endovascular coiling. However, our result was different from that of Otawara et al. ${ }^{18)}$ who demonstrated lower cognitive function in the ruptured aneurysm group compared with the unruptured group. We think our limited patient number might have masked differences between groups.

\section{Difference according to time interval}

We compared data from 59 patients who completed the K-MMSE more than once (Table 4). Although their pathologies and treatment modalities varied, $76.3 \%$ of (45 of 59) patients showed an improved K-MMSE score when they took the test again (mean: 11.9 months after the first test). However, it is unclear whether this change was due to cognitive function recovery or a practice effect due to repeated trials. Only one version of the questionnaire was available in our study, although other studies have utilized different versions administered in a random order to minimize practice effects. ${ }^{1)}$ Because there was an interval of 11.9 months between the two tests, we think that practice effect were not a significant contributor. Similar cognitive improvements were also documented in several non-brain surgeries studies. ${ }^{14) 15)}$ Moller et al. ${ }^{14)}$ indicated cognitive dysfunction in $25.8 \%$ and $9.9 \%$ of patients 1 week and 3 months after non-brain surgery, respectively. Newman et al. ${ }^{15)}$ documented cognitive dysfunction in $36 \%$ and $24 \%$ of patients 6 weeks and 6 months after cardiac surgery, respectively. Abildstrom et al. ${ }^{1)}$ reported that postoperative cognitive dysfunction is reversible in the majority of elderly patients after general surgery, such as major abdominal, non-cardiac thoracic, or orthopedic surgery with general anesthesia. Our results are different from those in non-brain surgery studies in two ways. First, our cognitive dysfunction rate was much higher, even after cognitive improvements. Although most pa- tients showed an improved K-MMSE score and the number of the patients with cognitive dysfunction decreased from 41 to $18(69.5 \%$ to $30.5 \%)$, many patients in our series still had cognitive dysfunction. The K-MMSE score did not show any linear correlation with the time interval between testing or with the time after treatment $(p>0.05)$. Therefore, we did not expect this improvement would continue. Second, our mean time from treatments to test was much longer than that observed in non-brain surgery. According to Moller et al., ${ }^{14)}$ dynamic cognitive improvement occurred within 3 months postoperatively. However, our study subjects showed similar improvement after a mean of 29.3 months postoperatively.

\section{Limitations of study}

Our study has some limitations. First, we could not compensate all of the factors that might possibly bias K-MMSE scores; cognitive function is not only affected by pathologies or treatment modalities, it may also be influenced by many complicated socio-cultural factors, such as age, gender, education level, social class, marital status or income. ${ }^{3) 5(7) 17)}$ This incomplete stratification and compensation stems from the uneven and relatively small number of patients, which is a drawback of recruiting various pathologies. Second, mortality and severe morbidity cases unable to visit the outpatient clinic were excluded from our study. We also excluded patients who refused to fill out our questionnaire. It is likely that there is something intrinsically different between people who volunteer for our study and those who do not. $^{13)}$ This is particularly true of neuropsychological studies, where personality traits might influence willingness to participate and test results. ${ }^{13)}$ Thus, our result might have limitation in representing all kinds of neurosurgical patients.

Despite these limitations, however, our study contains unique information about the cognitive function of general neurosurgical patients, which can be used as a normative data for Koreans. 


\section{CONCLUSION}

Over $62 \%$ of patients who underwent a brain operation or endovascular intervention suffer from cognitive dysfunction. In our study, cognitive dysfunction was more prevalent in patients with trauma or ischemic disease than in those with epilepsy or tumor. Although many patients showed improvement, it took time and the dysfunction was not completely resolved. More attention should be paid to neuropsychological complications, such as cognitive dysfunctions.

\section{REFERENCES}

1. Abildstrom H, Rasmussen LS, Rentowl P, Hanning CD, Rasmussen H, Kristensen PA, et al. Cognitive dysfunction 1-2 years after non-cardiac surgery in the elderly. ISPOCD group. International Study of Post-Operative Cognitive Dysfunction. Acta Anaesthesiol Scand. 2000 Nov;44(10): 1246-51.

2. Bowler JV. Editorial comment-dementia after stroke. Stroke. 2004 Jun;35(6):1268-9.

3. Brayne C, Calloway P. The association of education and socioeconomic status with the Mini Mental State Examination and the clinical diagnosis of dementia in elderly people. Age Ageing. 1990 Mar;19(2):91-6.

4. Chung FF, Chung A, Meier RH, Lautenschlaeger E, Seyone C. Comparison of perioperative mental function after general anaesthesia and spinal anaesthesia with intravenous sedation. Can J Anaesth. 1989 Jul;36(4):382-7.

5. Fillenbaum GG, Hughes DC, Heyman A, George LK, Blazer DG. Relationship of health and demographic characteristics to Mini-Mental State examination score among community residents. Psychol Med. 1988 Aug;18(3): 719-26.

6. Folstein MF, Folstein SE, McHugh PR. "Mini-mental state". A practical method for grading the cognitive state of patients for the clinician. J Psychiatr Res. 1975 Nov;12(3): 189-98.

7. Han C, Jo SA, Jo I, Kim E, Park MH, Kang Y. An adaptation of the Korean mini-mental state examination (K-MMSE) in elderly Koreans: demographic influence and populationbased norms (the AGE study). Arch Gerontol Geriatr. 2008 Nov-Dec;7(3):302-10.
8. Jensen BO, Hughes P, Rasmussen LS, Pedersen PU, Steinbruchel DA. Cognitive outcomes in elderly high-risk patients after off-pump versus conventional coronary artery bypass grafting: a randomized trial. Circulation. 2006 Jun; 113(24):2790-5.

9. Kang Y, Na DL, Hahn S.[A validity study on the korean mini-mental state examination (K-MMSE) in dementia patients.] J Korean Neurol Assoc. 1997 Apr; 15(2):300308. Korean.

10. Kim TH, Jhoo JH, Park JH, Kim JL, Ryu SH, Moon SW, et al. Korean version of mini mental status examination for dementia screening and its' short form. Psychiatry Investig. 2010 Jun; 7(2):102-8.

11. King JT Jr, DiLuna ML, Cicchetti DV, Tsevat J, Roberts MS. Cognitive functioning in patients with cerebral aneurysms measured with the mini mental state examination and the telephone interview for cognitive status. Neurosurgery. 2006 Oct;59(4):803-10; discussion 810-1.

12. Kreiter KT, Copeland D, Bernardini GL, Bates JE, Peery S, Claassen J, et al. Predictors of cognitive dysfunction after subarachnoid hemorrhage. Stroke. 2002 Jan;33(1):200-8.

13. Lewis MB, Howdle PD. Cognitive dysfunction and health-related quality of life in long-term liver transplant survivors. Liver Transpl. 2003 Nov;9(11):1145-8.

14. Moller JT, Cluitmans P, Rasmussen LS, Houx P, Rasmussen H, Canet J, et al. Long-term postoperative cognitive dysfunction in the elderly ISPOCD1 study. ISPOCD investigators. International Study of Post-Operative Cognitive Dysfunction. Lancet. 1998 Mar;351(9106):57-61.

15. Newman MF, Kirchner JL, Phillips-Bute B, Gaver V, Grocott H, Jones RH, et al. Longitudinal assessment of neurocognitive function after coronary-artery bypass surgery. N Engl J Med. 2001 Feb;344(6):395-402.

16. Newman S, Stygall J, Hirani S, Shaefi S, Maze M. Postoperative cognitive dysfunction after noncardiac surgery: a systematic review. Anesthesiology. 2007 Mar; 106(3):72-90.

17. O'Connor DW, Pollitt PA, Treasure FP, Brook CP, Reiss BB. The influence of education, social class and sex on Mini-Mental State scores. Psychol Med. 1989 Aug;19(3): 771-6.

18. Otawara Y, Ogasawara K, Kubo Y, Kashimura H, Ogawa A, Yamadate K. Comparison of postoperative cognitive function in patients undergoing surgery for ruptured and 
unruptured intracranial aneurysm. Surg Neurol. 2009 Dec; 72(6):592-5; discussion 595.

19. Park IS, Kim NS, Lim HJ, Jang SH.[Comparison of the Frequency of Postoperative Delirium in Elderly between General Anesthesia and Regional Anesthesia.] Korean J Anesthesiol. 1998 Mar;34(3):623-9. Korean.

20. Pereira-Filho AA, Pereira AG, Faria MB, Lima LC, Portuguez MW, Kraemer JL. Microsurgical clipping in forty patients with unruptured anterior cerebral circulation aneurysms: an investigation into cognitive outcome. Arq Neuropsiquiatr. 2010 Oct;68(5):770-4.

21. Sohn BK, Sung YB, Park EJ, Lee DW.[The Incidence and
Related Factors of Delirium in Elderly Patients with Hip Fracture after Surgery.] J Korean Geriatr Soc. 2010 Sep; 14(3):162-70. Korean.

22. Tuffiash E, Tamargo RJ, Hillis AE. Craniotomy for treatment of unruptured aneurysms is not associated with long-term cognitive dysfunction. Stroke. 2003 Sep;34(9): 2195-9.

23. van Dijk D, Spoor M, Hijman R, Nathoe HM, Borst C, Jansen EW, et al. Cognitive and cardiac outcomes 5 years after off-pump vs on-pump coronary artery bypass graft surgery. JAMA. 2007 Feb;297(7):701-8. 